\title{
A simplified model for the estimation of life-cycle greenhouse gas emissions of enhanced geothermal systems
}

\author{
Martino Lacirignola ${ }^{1 *}$, Bechara Hage Meany ${ }^{2,4}$, Pierryves Padey ${ }^{3}$ and Isabelle Blanc ${ }^{4}$
}

\author{
* Correspondence: \\ martino.lacirignola@ademe.fr \\ ${ }^{1}$ Energy Networks and Renewable \\ Energy Department, French \\ Environment and Energy \\ Management Agency (ADEME), 27 \\ rue Louis Vicat, Paris 75737, France \\ Full list of author information is \\ available at the end of the article
}

\begin{abstract}
Background: The development of 'enhanced geothermal systems' (EGS), designed to extract energy from deep low-enthalpy reservoirs, is opening new scenarios of growth for the whole geothermal sector. A relevant tool to estimate the environmental performances of such emerging renewable energy (RE) technology is Life Cycle Assessment (LCA). However, the application of this cradle-to-grave approach is complex and time-consuming. Moreover, LCA results available for EGS case studies cover a fairly high variability range.

Methods: A new type of LCA-based approach, called simplified model, is developed based on the analysis of environmental performance variability of energy pathways. Such methodology has been applied to produce a reduced parameterized model, designed to estimate life-cycle greenhouse gas (GHG) emissions of EGS power plants applicable to a large sample of configurations.
\end{abstract}

Results: Two parameterized models to assess EGS greenhouses gases (GHG) are the outcomes of this study. A parameterized reference model is developed to describe a large sample of possible EGS power plants located in central Europe. Two or three wells plants equipped with a binary system producing only electricity are accounted for. Applying global sensitivity analysis (GSA) to this reference model allows the identification of three key variables, responsible for most of the variability on GHG results: installed power capacity, drilling depth, and number of wells. A reduced parameterized model for the estimate of the GHG performances as the only function of these three key variables is then established. A comparison with the results of published EGS LCAs confirms the representativeness of our new simplified model.

Conclusions: Our simplified model, issued from the reference parameterized model, enables a rapid and simple estimate of the environmental performances of an EGS power plant, avoiding the extensive application of the LCA methodology. It provides an easy-to-use tool for the stakeholders of the EGS sector and for decision makers. It aims at contributing to the debate about the performances of this new emerging technology and its related environmental impacts.

Keywords: Simplified model; Life-cycle assessment; Enhanced geothermal systems; Global sensitivity analysis

\section{Springer}

(c) 2014 Lacirignola et al.; licensee Springer. This is an Open Access article distributed under the terms of the Creative Commons Attribution License (http://creativecommons.org/licenses/by/2.0), which permits unrestricted use, distribution, and reproduction in any medium, provided the original work is properly credited. 


\section{Background}

Renewable energy (RE) systems are currently playing a major role in the electricity sector, accounting in 2012 for about half of the new installed power capacity worldwide. Such a strong growth is promoted by the implementation of supporting energy policies in several countries, with the aim of reducing greenhouse gas (GHG) emissions (REN21 2013).

Although the operation phase of most RE-based systems does not entail direct emissions related to the combustion of fossil fuels, the industrial processes related to the manufacturing or the installation of such devices may have significant impacts to the environment (Varun et al. 2009; Ardente et al. 2008; Pacca et al. 2007). Geothermal binary systems using low-enthalpy reservoirs are an example: the construction of the wells for this technology, requiring large quantities of energy and materials, is the most influential process on the overall environmental performance, with the largest GHG emissions over all processes (Frick et al. 2010).

In the RE domain, the recent development of 'enhanced geothermal systems' (EGS) is attracting attention as a promising technology for the valorization of low-temperature geothermal resources reached with deep boreholes in specific areas (Glassley 2010). In particular, the EGS sector is attracting interest in central Europe, especially in the area of the Rhine Graben between France and Germany. Following the installation of a pilot plant in Soultz-sous-Forêts (France), an EGS plant was built in Landau (Germany), another is under construction near Rittershoffen (France), and several exploration permits in the same zone have been requested to the national authorities. In Europe, many other areas present favorable geological conditions for EGS applications, for example Hungary, Serbia, Romania, Spain, and Turkey (Hurtig et al. 1992). A rapid expansion of this sector is foreseen (Holm et al. 2010).

The more elaborate realization of the wells and the surface facilities raised questions about the environmental performances of EGS, highlighting the need to consider all the stages of the lifecycle of the plant in order to perform a consistent analysis. A relevant methodology to investigate the overall environmental impacts of RE technologies from a 'cradle-to-grave' perspective is the Life Cycle Assessment (LCA) (Ness et al. 2007). The LCA methodology has been standardized with the ISO 14040 series. It is based on the estimation of the environmental impacts of a product taking into account all processes related to its life cycle, such as the extraction of raw materials, manufacturing, distribution, use, and disposal (ISO 14040 2006; ISO 14044 2006).

A large amount of LCAs has been published so far for several RE technologies, comparing their GHG emissions among each other and to those of conventional power plants. Since most of these studies assessed the overall suitability of RE systems, the variability of the results is fairly high. For example, a recent IPCC report, based on the compilation of about 50 LCAs of wind turbines, presented a fairly wide range of GHG emissions from 2 to $81 \mathrm{gCO}_{2} \mathrm{eq} / \mathrm{kWh}$. For geothermal systems (including EGS power plants), LCA results from this IPCC study range from 6 to $79 \mathrm{gCO}_{2} \mathrm{eq} / \mathrm{kWh}$ (Moomaw et al. 2011).

However, compared to other RE technologies, LCA studies reported in the geothermal field are not abundant. The so far published results are in some cases quite general (Pehnt 2006), or conversely can be specific to a particular geographical area (Hondo 2005). In general, the results of single LCAs may be only representative for a specific technology 
and subjected to a number of hypotheses and limitations (for example regarding transports and type of accounted materials). Today, the implementation of supporting policies and the evaluation of promoted plants need the contribution of further LCA studies in the geothermal field.

The elaboration of a LCA is pretty time-consuming, especially through the collection of data relating to the input and outputs of materials and energy flows over the lifecycle of the assessed system. To avoid undertaking complete LCAs of alternative plant setups requires moving for a different type of approach, considering a panel of technical concepts in a defined geological region. Moreover, in the context of the growth of the EGS sector, the availability of a simpler and easier tool than LCA to estimate the GHG emissions would be helpful for decision makers.

The meta-LCA methodology tried to consider energy pathways globally (i.e., a set of systems instead of a single one) to overcome the undertaking of single-detailed LCAs and has been widely used in the energy field over the last few years (Warner et al. 2010). The meta-LCA is based on the cross comparison of literature sources: the selected studies are harmonized into a common framework (e.g., same lifetime, same characterization factors, etc.). The variance induced by each parameter is assessed one factor at a time and its relative contribution to the environmental performances is measured. Two outcomes are possible: a reduced range of emissions' estimation (compared to a generic literature review of single LCAs) and in some case meta-models (Lenzen 2008) which enable to estimate environmental impacts of the literature using a simple linear regression model. However, in both cases, the results rely only on the representativeness of literature data and cannot compensate for the lack of data or specific case studies in literature.

Recently, Padey et al. (2013) presented a new methodology to address these issues for the wind electricity pathway, with the elaboration of a framework to develop simplified models able to estimate GHG emissions for a large sample of case studies not restricted to those already available in literature. It relies on the quantitative assessment of the variability and the identification of a restricted number of key parameters that are responsible for most of the variability on the environmental performances. A simplified model is then developed to estimate the environmental impacts of systems that compose the energy pathway as a function of these few key variables. This approach provides a simple tool for policy makers that covers a wide range of possible configurations of the energy system. Such methodology represents an intermediate solution between the detailed LCA and the meta-LCA (Blanc et al. 2013): it aims at quantifying the overall environmental profile of an energy pathway while estimating the environmental impacts of its embedded systems.

Given the need for easy-to-use and reliable tools for environmental analysis to promote the development of enhanced geothermal systems, this study aims at developing such a simplified model specific to the EGS sector assessing the GHG performances. In this paper, we define two parameterized models applying to the EGS pathway the methodology described by Padey et al. (2013). Starting from a representation of a general parameterized model for EGS power plants (called 'reference model'), a limited number of parameters that explain most of the variability on GHG results of potential various configurations are identified: installed power capacity, drilling depth, and number of wells. Hence, a reduced parameterized model (called 'simplified model') is developed, 
representing the GHG emissions as a function of only those three key parameters. Then, to assess the robustness of the model, a comparison between specific results available from LCA literature and outcomes of the simplified model is presented and analyzed.

\section{Methods and Results}

The methodology to generate the parameterized models representative of life cycle GHG emissions per electricity produced for the EGS pathway is based on the following steps (Padey et al. 2013):

1. Definition of the objective and scope of the parameterized models.

2. Design of the reference model and generation of the EGS GHG distribution profile by applying Monte Carlo simulations.

3. Identification of the key parameters using generalized variance decomposition (Sobol Indices) by means of a global sensitivity analysis.

4. Definition of the simplified model based on the identified key parameters.

5. Comparison of the simplified model results with literature and assessment of its representativeness.

\section{Definition of the objective and scope of the model}

The objective of this study is to obtain an estimate of the life cycle GHG emissions of EGS power plants. The functional unit is the net energy produced over the life cycle, which means that the results will be expressed in terms of grams of $\mathrm{CO}_{2}$ equivalent per electrical $\mathrm{kWh}$ delivered to the grid.

EGS power plants, being binary systems, do not generate direct GHG emissions related to the energy production unlike their hydrothermal flash and dry steam counterparts (Sullivan et al. 2013). Life cycle emissions are principally caused by the construction phase. During operation, their GHG emissions are also only related to the infrastructure (e.g., transport of new equipment for replacement, disposal of filter residues and scaling).

The EGS power plants included in the analysis are characterized as follows:

Technological characterization: the systems considered have two or three wells reaching depths of 2 to $6 \mathrm{~km}$ and are equipped at the surface with an Organic Rankine Cycle (ORC). The plants produce only electricity (no cogeneration). The reservoir enhancement techniques taken into account are hydraulic and chemical stimulations. Geographical characterization: the study focuses on EGS power plants installed in central Europe.

Temporal characterization: the study takes into account current technologies for all equipment. Currently, EGS project developers in the Rhine Graben focus on depths of about $3 \mathrm{~km}$, since one of the lessons learned from Soultz's pilot is that drilling up to $5 \mathrm{~km}$ is not economically optimal today (Genter et al. 2010). However, this study takes into account the possibility of drilling down to $6 \mathrm{~km}$ since this may become more economically viable in the near future thanks to the progress of the exploration and drilling techniques.

Methodological characterization: the life cycle inventory (LCI), namely the compilation of all inputs and outputs (e.g., materials, emissions) from the processes occurring in the life cycle of an EGS plant, is based on the one proposed by Lacirignola and Blanc 
(2013). This paper is mainly based on technical data from the Soultz-sous-Forêts site. It also presents a multi-criteria environmental assessment of ten alternative plant setups, with two or three wells and a final power output ranging from 0.8 to 3.1 MW. Data regarding background processes, such as raw material extraction or transports are retrieved from the ecoinvent database v2.2 (Ecoinvent Centre 2010). The characterization factors used to calculate the GHG are based on the IPCC reports (Bernstein et al. 2008).

\section{Design of the reference model}

To cover a representative EGS pathway with the reference model, a large sample of possible EGS plants must be accounted for.

The environmental performances of each EGS power plant of the sample are calculated as

$$
\text { GHG performances of EGS }=\frac{\text { GHG emissions }\left[\mathrm{gCO}_{2 \mathrm{eq}}\right]}{\text { Electricity production }[\mathrm{kWh}]}
$$

The numerator represents the total amount of GHG emissions expressed in equivalent mass of $\mathrm{CO}_{2}$ of all processes related to the life cycle of the plant. Those are calculated from the GHG of an explicit life cycle inventory (LCI) using the IPCC GHG characterization factors (Bernstein et al. 2008). These characterization factors are used to quantitatively convert each GHG according to their respective Global Warming Potential related to $\mathrm{CO}_{2}$, the reference gas. Further information on such calculation process can be found in Heijungs (1996) and in Jolliet et al. (2003).

The denominator is the amount of electricity delivered to the grid over the lifetime, calculated as

$$
\text { Electricity production }=P_{\mathrm{NET}} \times \mathrm{LF} \times 8,760 \times \mathrm{LT}
$$

Where $P_{\mathrm{NET}}$ is the final power output of the EGS plant. $P_{\mathrm{NET}}$ is the difference between the ORC installed capacity $P_{\text {ORC }}$ (namely the power output of the electric generator minus the power absorbed by the other ORC equipment, like the air cooler) and $P_{\text {pumps }}$ (the power demand of the pumps for the production and the reinjection of the geothermal fluid). LF is the load factor (a fraction ranging from 0 to 1 expressing the amount of equivalent operating hours at nominal power in 1 year), 8,760 is the total number of hours over 1 year, and LT is the lifetime of the plant (expressed in years).

The large sample of possible EGS power plants is generated from a reference model based on nine parameters: produced flow rate, drilling depth, number of wells, fuel consumption for drilling, load factor, power demand of the pumps, enhancement's intensity, lifetime, power capacity of the ORC. These nine parameters are described in section 'Parameters description' and reported in Table 1. They are identified as sufficient to calculate the GHG performances according to Equation 1 (all other variables are defined as related to them). They have been selected as they allow for the characterization of the size of the plant, of the inventory of materials involved and of the amount of electricity produced over the life cycle. The nine parameters of our model are mathematically independent: this is a necessary condition for the application of the global sensitivity analysis (GSA), which will be performed to identify the parameters that are responsible 
Table 1 Parameters characterization for the reference model (Equation 3)

\begin{tabular}{|c|c|c|c|c|c|}
\hline Symbol & Parameter & Value range & Unit & $\begin{array}{l}\text { Probability distribution } \\
\text { in the value range }\end{array}$ & Main references \\
\hline$z$ & Borehole depth & 2,000 to 6,000 & $\mathrm{~m}$ & Equiprobability & $\begin{array}{l}\text { Current EGS projects }^{\mathrm{a}}, \\
\text { Genter et al. (2010), } \\
\text { Frick et al. (2010), } \\
\text { Bauer et al. (2008) }\end{array}$ \\
\hline$f$ & $\begin{array}{l}\text { Produced flow } \\
\text { rate }\end{array}$ & 25 to 100 & $\mathrm{~kg} / \mathrm{s}$ & Equiprobability & $\begin{array}{l}\text { Current EGS projects }{ }^{a}, \\
\text { Frick et al. (2010) }\end{array}$ \\
\hline Nw & Number of wells & 2 to 3 & Adimensional & Equiprobability & $\begin{array}{l}\text { Current EGS projects }{ }^{\text {a }} \\
\text { Huenges (2010), Bauer } \\
\text { et al. (2008), Schmidt } \\
\text { et al. (2010) }\end{array}$ \\
\hline$d$ & Fuel for drilling & 3,000 to 7,000 & $\mathrm{MJ} / \mathrm{m}$ & Equiprobability & $\begin{array}{l}\text { Drilling reports from } \\
\text { Soultz-sous-Forêts }{ }^{\mathrm{b}}, \\
\text { Bauer et al. (2008), } \\
\text { Frick et al. (2010) }\end{array}$ \\
\hline LF & Load factor & 0.85 to 0.95 & Adimensional & Equiprobability & $\begin{array}{l}\text { Lund (2003), Huenges } \\
\text { (2010), Platt et al. (2012) }\end{array}$ \\
\hline LT & Lifetime & 20 to 40 & years & $\begin{array}{l}\text { Normal distribution } \\
\text { centered on } \mathrm{LT}=30 \text { years } \\
\text { with } \sigma=3.25\end{array}$ & $\begin{array}{l}\text { Frick et al. (2010), Platt } \\
\text { et al.(2012), Bauer et al. } \\
\text { (2008), Huenges (2010) }\end{array}$ \\
\hline SFe & $\begin{array}{l}\text { Scaling factor } \\
\text { enhancement }\end{array}$ & 0.5 to 10 & Adimensional & $\begin{array}{l}\text { Lognormal distribution } \\
\text { with } \sigma=1, \mu=0 \text { and } \\
\text { peak on SFe }=1\end{array}$ & $\begin{array}{l}\text { Schindler et al. (2010), } \\
\text { Hettkamp et al. (2004), } \\
\text { Nami et al. (2008), Graff } \\
\text { and Baujard (personal } \\
\text { communication) }\end{array}$ \\
\hline$P_{\mathrm{p}}$ & $\begin{array}{l}\text { Specific power } \\
\text { of pumps }\end{array}$ & 3.6 to 8.6 & $\mathrm{~kW} /(\mathrm{kg} / \mathrm{s})$ & Equiprobability & $\begin{array}{l}\text { Frick et al. (2010), } \\
\text { Lacirignola and Blanc } \\
\text { (2013), Graff and Baujard } \\
\text { (personal communication }\end{array}$ \\
\hline$P_{\text {ORC }}$ & $\begin{array}{l}\text { Installed capacity } \\
\text { ORC }\end{array}$ & 1,250 to 3,500 & kW & Equiprobability & $\begin{array}{l}\text { Current EGS projectsa, } \\
\text { Huenges (2010), Bauer } \\
\text { et al. (2008) }\end{array}$ \\
\hline
\end{tabular}

${ }^{a}$ Current EGS projects taken into account in this study (see also Additional file 1 section 2): Soultz-sous-Forêts (France): Genter (2011), LabEx G-EAU-THERMIE PROFONDE (2013); Landau (Germany): Hettkamp et al. (2011), Frey and Milles (2007); Rittershoffen (France): Perret (2011), Schmittbuhl (2013); Insheim (Germany): Baumgärtner (2011), Bestec (2012). ${ }^{b}$ Drilling reports from Soultz-sous-Forets power plant: G.E.I.E. Exploitation Minière de la Chaleur (2002), Southern International Inc (2002), Gandy Inc (2004a, 2004b).

for most of the variation of the GHG performances (section 'Key parameter identification').

\section{Generation of an explicit $\mathrm{LCl}$ model}

Our reference model is represented in Figure 1 and is here described. Supplementary information are provided in Additional file 1 (sections 1 and 5). Blue boxes in Figure 1 refer to the nine parameters mentioned above.

The explicit LCI is modular and disaggregated into four LCIs (orange boxes): the wells LCI, the ORC LCI, the pumps of the geothermal loop LCI, and the enhancement phase LCI.

The LCI of the wells, the ORC, and the pumps are obtained with a scaling approach from the EGS data regarding materials and processes published by Lacirignola and Blanc (2013) (e.g., for the ORC, we follow the assumption of a linear relation between the amount of material needed and the power installed, as in Frick et al. 2010). Such data are represented by the black boxes in Figure 1. Although in some cases the relation 


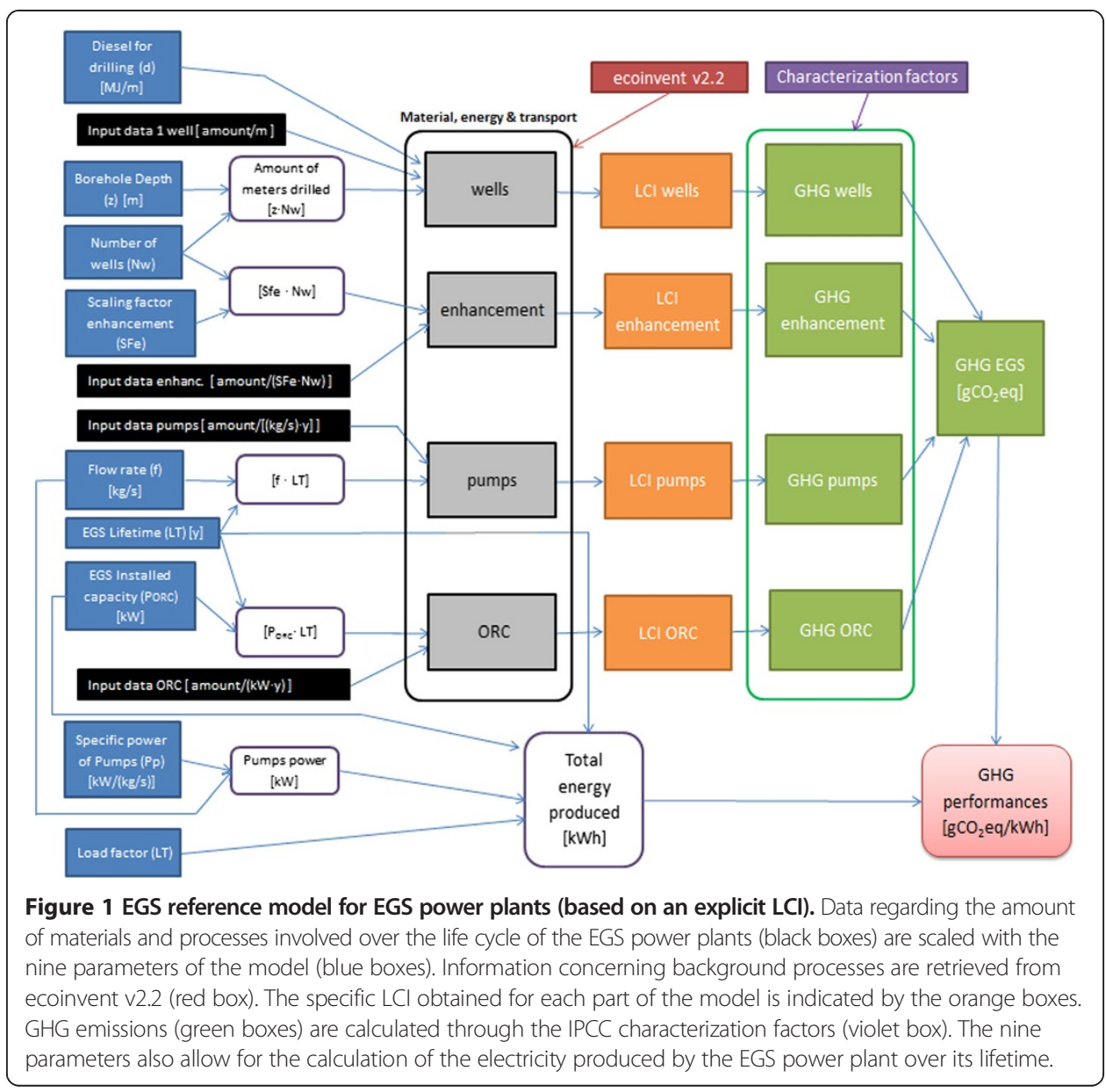

between the size of a plant's component and the amount of its materials is not linear, such scaling approach simplifies the process of compiling LCIs for a large sample of scenarios. The replacement rate of equipment follows the hypothesis of Lacirignola and Blanc (2013).

The LCI of the wells covers information regarding the drilling process (i.e., fuel consumption, mud circulation), casing, and cementation.

The LCI of the ORC includes data regarding the electric generator, ORC turbine, circulation pump, air cooler, filters, pipes, and other surface elements as described in Lacirignola and Blanc (2013).

The values of the $\mathrm{LCI}$ of the pumps are assumed to be proportional to the flow rate circulating in the geothermal loop. Each well is equipped with either a production or a reinjection pump.

The LCI for the enhancement process includes data concerning the quantity of water, salt, and hydrochloric acid for the hydraulic and chemical stimulation, necessary to improve the boreholes' productivity.

\section{Parameter description}

The large sample of possible EGS scenarios corresponds to random sets of the nine parameters. Each of these can take values within a fixed range and according to a 
probability distribution that we established, as presented in Table 1. The GHG profile of our sample is then produced through Monte Carlo simulations.

Value ranges and probability distributions have been established based on technical survey, literature review, and discussion with experts and reflect the current technical knowledge on EGS. Supplementary information on the nine parameters are provided in the Additional file 1 (sections 2 to 4).

- Drilling depth It depends on the geology and on techno-economic factors, given the high costs related to the construction of wells. A values range of 2 to $6 \mathrm{~km}$ is set, based on literature and current projects (see Table 2).

- Flow rate It depends on the geological conditions as well as on the success of the drilling and stimulation phases. A reasonable range of values (25 to $100 \mathrm{~kg} / \mathrm{s}$ ) is assumed for this parameter in accordance with current EGS experiences. Since the characteristics of the geothermal resource are extremely site dependent, no specific probability distribution is established within the boundaries of the flow rate and the drilling depth.

- Number of wells Current EGS applications in Europe rely on a limited number of wells (two or three), because of the high construction costs. In addition, the seismicity risk related to the reinjection of high flow rates is emerging as a key factor for the design of the plant (Lacirignola and Blanc 2013), especially after the relevant seismic events in Basel and Landau (Schmidt et al. 2010; Gross et al. 2013). The correlation between the circulation strategy (number of wells used for the reinjection) and the seismicity risk is extensively discussed in Lacirignola and Blanc (2013). Given that the underground architecture depends on technical and economic site-dependent factors, two equiprobable values are considered (two or three wells). It is assumed that, for the three-well scenarios, the most appropriate reinjection strategy is put in place (i.e., use of two

Table 2 Selection of case studies from literature used for comparison

\begin{tabular}{|c|c|c|c|c|c|}
\hline Code & $\begin{array}{l}\text { Case study from } \\
\text { literature }\end{array}$ & $\begin{array}{l}\text { Depth } \\
(z)[\mathrm{m}]\end{array}$ & $\begin{array}{l}\text { Number of } \\
\text { wells (Nw) }\end{array}$ & $\begin{array}{l}\text { Installed capacity } \\
\left(\mathrm{P}_{\mathrm{ORC}}\right)[\mathrm{kW}]\end{array}$ & $\begin{array}{l}\text { Estimate of } \mathrm{GHG} \\
\text { performances }\left[\mathrm{gCO}_{2} \mathrm{eq} / \mathrm{kWh}\right]\end{array}$ \\
\hline FA1 & Frick et al. (2010) - SiteA1 & 3,800 & 2 & 1,240 & 54 \\
\hline FB1 & Frick et al. (2010) - SiteB1 & 4,700 & 2 & 1,290 & 53 \\
\hline $\mathrm{PtO}$ & Platt et al. (2012) - 'ORG' site & 3,162 & 2 & $1,740^{\mathrm{a}}$ & 23 \\
\hline PtS & Platt et al. (2012) - 'SMB' site & 4,307 & 2 & $2,870^{a}$ & 19 \\
\hline $\mathrm{Ba}$ & Bauer et al. (2008) & 5,500 & 3 & $2,940^{\mathrm{a}}$ & 27 \\
\hline Hu1 & Huenges (2010) - case 1 & 4,000 & 2 & 1,440 & 58 \\
\hline Hu2 & Huenges (2010) - case 2 & 4,000 & 2 & 1,440 & 55 \\
\hline LBa & $\begin{array}{l}\text { Lacirignola and Blanc } \\
\text { (2013) - base case }\end{array}$ & 4,000 & 3 & 1,820 & 37 \\
\hline Su & Sullivan et al. (2013) & 6,000 & 10 & 20,000 & 18.9 \\
\hline
\end{tabular}

${ }^{a}$ For Bauer et al. (2008), the auxiliary power demand of the ORC equipment is assumed to be $2 \%$ of the generator's output, considering that the total auxiliary demand (including the pumps of the geothermal loop) amounts to $4 \%$. For Platt et al. (2012), the auxiliary power demand of the ORC equipment is assumed to be $20 \%$ of the generator's output considering that the total auxiliary demand accounted in its study (including the pumps of the geothermal loop) amounts to $37 \%$. 
boreholes for reinjection to minimize the risk of induced seismicity in case of a high produced flow rate).

- Fuel for drilling Several authors show that the construction of the wells is the most impacting process over the lifetime of an EGS (Lacirignola and Blanc 2013; Frick et al 2010; Huenges 2010). This is essentially due to the large quantity of fuel burnt in stand-alone electric generators during the drilling process. Being such a critical factor for the environmental performances of the plant, a large variability (3,000 to 7,000 MJ per meter drilled) of this site-dependent parameter is considered, allocating same probability for the values of this interval. This is based on literature and data from Soultz-sous-Forêts.

- Load factor The load factor is assumed to be $85 \%$ to $95 \%$ (7,446 to 8,322 equivalent full load hours per year) based on literature review. According to Lund (2003), geothermal plants have a load factor frequently above $90 \%$. Huenges (2010) and Platt et al. (2012) assume 7,500 h/year in their studies.

- Lifetime To date, no EGS in Europe is at end of its lifetime nor has been dismantled. In several case studies from the literature (Bayer et al. 2013; Platt et al. 2012; Bauer et al. 2008), 30 years is assumed. The minimum value is set to 20 years as proposed by Huenges (2010) and used in some scenarios by Frick et al. (2010). The maximum value is set to 40 years. A Gaussian probability distribution centered on 30 years (standard deviation of 3.25) is applied to this interval.

- Scaling factor for enhancement The stimulation of the reservoir is a critical phase for the success of an EGS project. Since this phase is extremely site dependent, a set of values for a 'base case' stimulation is defined based on current EGS experiences. Then, in order to take into account different scenarios (e.g., necessity of a strong enhancement campaign to improve the boreholes' productivity), these values are multiplied by a scaling factor (SFe) ranging from 0.5 to 10 and weighted through a lognormal distribution.

- Specific power of the pumps As previously discussed, the estimate of the power demand of the pump of the geothermal loop is necessary to calculate $P_{\mathrm{NET}}$. Such consumption is assumed to increase linearly with the flow rate. It is also assumed that all the pumps (for production and reinjection) are characterized with the same power to flow rate ratio. Following discussions with experts (Graff and Baujard, personal communication) and literature survey (Frick et al. 2010; Huenges 2010), the required power for the circulation in the geothermal loop is assumed to be 3.6 to $8.6 \mathrm{~kW} /(\mathrm{kg} / \mathrm{s})$ (all values are equiprobable).

Installed power capacity The variability range of the ORC power output is set to 1,300 to $3,500 \mathrm{~kW}$ according to the case studies used for comparison and current EGS projects.

Indeed, the installed power capacity of EGS $\left(P_{\mathrm{ORC}}\right)$ depends on many factors including for example the flow rate, the fluid temperature, the thermal efficiency, and the heat capacity (those parameters are also interrelated and depend on depth and geological conditions). However, it is not possible to generalize all the correlations among all those elements with simple equations widely valid in central Europe (using too generic functions, the uncertainty on GHG results would be too high). In our model, $P_{\mathrm{ORC}}$ intrinsically incorporates the combinations of all the factors mentioned above. In addition, it is an easy accessible variable: ORC suppliers usually 
refer to their equipment in terms of the power capacity of the system. For these reasons, we selected $P_{\mathrm{ORC}}$ as an input variable.

The application of the global sensitivity analysis (detailed in section 'Key parameter identification') is undertaken, even though there is a physical relationship between the flow rate, the number of wells, and the installed capacity: no mathematical correlation is established among them. The model takes into account random combinations of values taken from their respective variability intervals.

Such Monte Carlo random sampling may generate some unlikely scenarios (e.g., an EGS plant with a very limited power capacity despite a very high flow rate). The general strategy to exclude these cases consists in introducing a mathematical correlation between the dependent parameters and applying GSA only among the independent ones. However, as explained before, establishing such correlation is not worth considering in our case. Furthermore, such unlikely scenarios do not have high influence on the results (see 'Discussion').

\section{Reference model's equation}

The reference model's equation (3) is obtained by developing Equation 1, as represented in Figure 1. The numerator of Equation 1 (GHG emissions of the EGS power plant) can be expressed as the sum of the contribution of the four parts of the model (as detailed in section 'Generation of an explicit LCI model': wells, ORC, pumps and enhancement phase). GHG emissions are calculated from data regarding life cycle input and outputs of materials and energy flows (reported in Additional file 1 section 1) and their IPCC GHG characterization factors.

The denominator of Equation 1 (electricity produced) can be expressed by Equation 2 . Hence, we obtain Equation 3:

$$
\mathrm{GHG}_{\mathrm{EGS} \_ \text {Ref }}=\frac{z \times \mathrm{Nw} \times\left(\alpha_{1}+\alpha_{2} \times d\right)+\mathrm{LT} \times f \times \alpha_{3}+P_{\mathrm{ORC}} \times \mathrm{LT} \times \alpha_{4}+\mathrm{Nw} \times \mathrm{SFe} \times \alpha_{5}}{\mathrm{LT} \times \mathrm{LF} \times\left(P_{\mathrm{ORC}}-f \times P_{\mathrm{p}}\right) \times 8,760}
$$

with

$$
\begin{aligned}
& \alpha_{1}=567,014.8\left[\mathrm{gCO}_{2 \mathrm{eq}} / \mathrm{m}\right] ; \alpha_{2}=86.49\left[\mathrm{gCO}_{2 \mathrm{eq}} / \mathrm{MJ}\right] ; \alpha_{3}=411,384\left[\mathrm{gCO}_{2 \mathrm{eq}} \times \mathrm{s} /(\mathrm{kg} \times \text { year })\right] \\
& \alpha_{4}=43,139\left[\mathrm{gCO}_{2 \mathrm{eq}} /(\mathrm{kW} \times \text { year })\right] ; \alpha_{5}=65,017,978.7\left[\mathrm{gCO}_{2 \mathrm{eq}}\right]
\end{aligned}
$$

In this equation, $z$ is the borehole depth $(\mathrm{m}), f$ is the total produced flow rate $(\mathrm{kg} / \mathrm{s})$, $\mathrm{Nw}$ is the number of wells, $d$ represents the amount of fuel for drilling (MJ per meter drilled), LF is the load factor (dimensionless), LT is the lifetime (years), SFe is the enhancement factor (dimensionless), $P_{\mathrm{ORC}}$ is the ORC power output $(\mathrm{kW})$, and $P_{\mathrm{p}}$ is the specific power of the pumps $(\mathrm{kW} /(\mathrm{kg} / \mathrm{s}))$.

The $\alpha_{i}$ constants correspond to the values of the GHG emissions of each part of the model. For the wells, $\alpha_{2}$ is related to diesel consumption and $\alpha_{1}$ related to all other drilling processes (e.g., casing, cementation, mud circulation).

Given such parametric representation (expressed by Equation 3 and shown in Figure 1), the definition of a vector containing a specific value for each one of the nine parameters (e.g., number of wells $=2$, total produced flow rate $=50 \mathrm{~kg} / \mathrm{s}$, lifetime $=30$ years, 
and so on) leads to the generation of a new LCI. Each new set of nine parameters corresponds to a different EGS scenario. Hence, the GHG performances can be calculated for a large panel of case studies, accounting many possible combinations of values of the nine parameters.

\section{Model verification}

The GHG results of the reference model, obtained through Monte Carlo simulations over 50,000 random EGS scenarios are presented in Figure 2 and compared to literature. The top and bottom of the box represent the 25th and the 75th percentile, while the middle line is the median (around $30 \mathrm{gCO}_{2} \mathrm{eq} / \mathrm{kWh}$ ). The whiskers indicate the 5th and the 95th percentile. We observe that the results are comparable with literature, indicating that the selected parameters and the chosen variability intervals can sufficiently represent EGS power plants. The IPCC result range is larger since it is compiled from publications regarding all type of geothermal plants (not limited to EGS). The literature reference ' $c$ ' (Frick et al. 2010, case 'C1') displays very low emissions as it corresponds to a quite optimistic scenario for EGS power plants: despite having only two wells, an electrical power output of more than $10 \mathrm{MW}$ is assumed (supposing a production flow rate of about $140 \mathrm{~kg} / \mathrm{s}$ at $200^{\circ} \mathrm{C}$ ); moreover the lifetime of the plant is set to 40 years.

Once the robustness of our reference model has been verified through this consistency check, we proceed to the identification of the key parameters.

\section{Key parameter identification}

For the identification of the key parameters, namely those that are responsible for most of the variability in the GHG performances over our large sample of EGS configurations, a global sensitivity analysis (GSA) is performed. The main output of GSA is the estimate of the Sobol Indices (SI) of each parameter. The contribution of each parameter alone to the overall variance of GHG performances is represented by the first-order Sobol index.

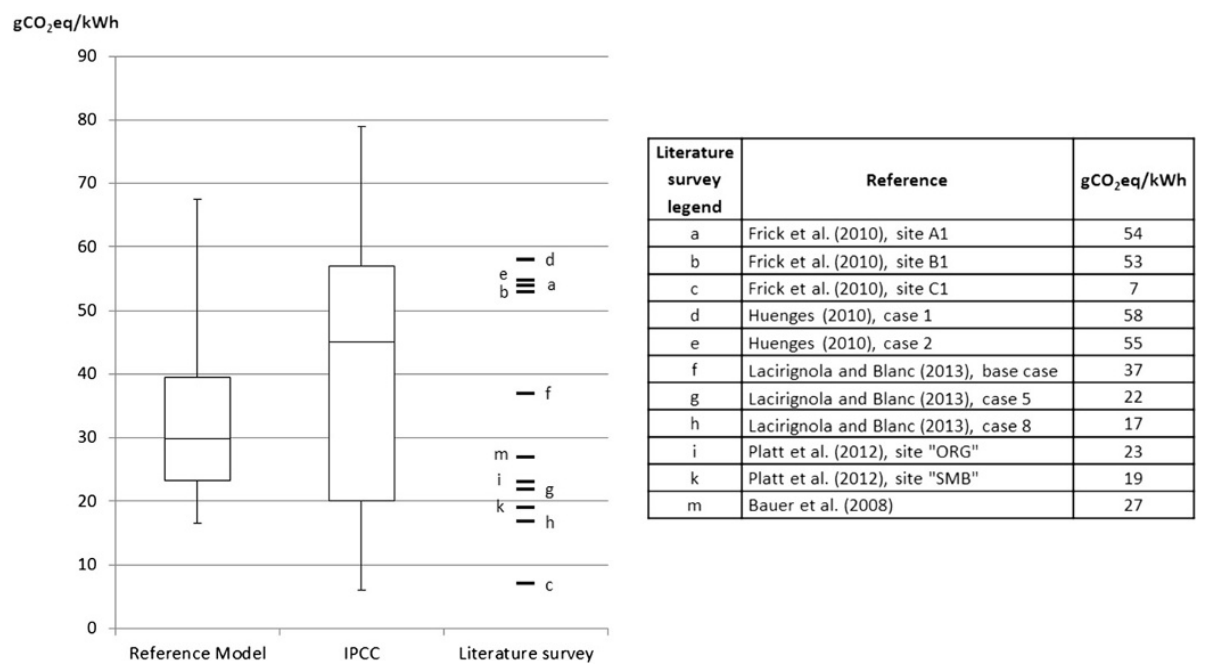

Figure 2 GHG performances: comparison between the results of reference model (left) and literature. Center: LCA results for geothermal plants (all kinds) as presented in Moomaw et al. (2011) in the IPCC Special Report on Renewable energy sources and climate change mitigation. Right: LCA results for EGS plants (authors and case studies selected from literature, see legend in the table). 
The total order Sobol index describes the influence of the parameter itself plus all its combination with the other eight (total order SI is the sum of all SI of the variable, including higher order indices that express the variance of groups of variables). Hence, a higher first-order SI implies that a parameter is responsible for a higher share of the variance on GHG results. Further details about the GSA methodology and Sobol indices are provided in Sobol (2001) and Iooss (2011).

The results of the application of GSA to our reference model are presented in Figure 3. First-order Sobol Indices are presented with the blue bars; these indices are used to identify, among the nine parameters, the ones that will be used for the simplified model. Red bars display the total order indices.

From Figure 3 and according to our reference model, we observe that the installed capacity alone is responsible for almost half of the variability of GHG performances of EGS power plants, having a first-order SI of about 0.5. Note that this does not mean that the size of the ORC is the main cause of GHG emissions: it means that it has a high influence on the variability of the environmental performances considering the scope of our reference model, namely the emissions per unit of electricity delivered to the grid. The drilling depth is also of high relevance (first-order SI approximately 0.17) followed by the number of wells (first-order SI approximately 0.10).

Based on these results, three variables are selected as key parameters: installed capacity, drilling depth, and number of wells. Together, they are responsible for about $75 \%$ of the variance of GHG performances over the sample of studied configurations.

The definition of the amount of key parameters to be used in the simplified model is based on a trade-off between accuracy and simplification. For instance, we could have neglected the number of wells, establishing a simplified model only based on the two parameters (installed capacity and drilling depth) that together are responsible for about $65 \%$ of the variability of results. However, by using three key parameters, the

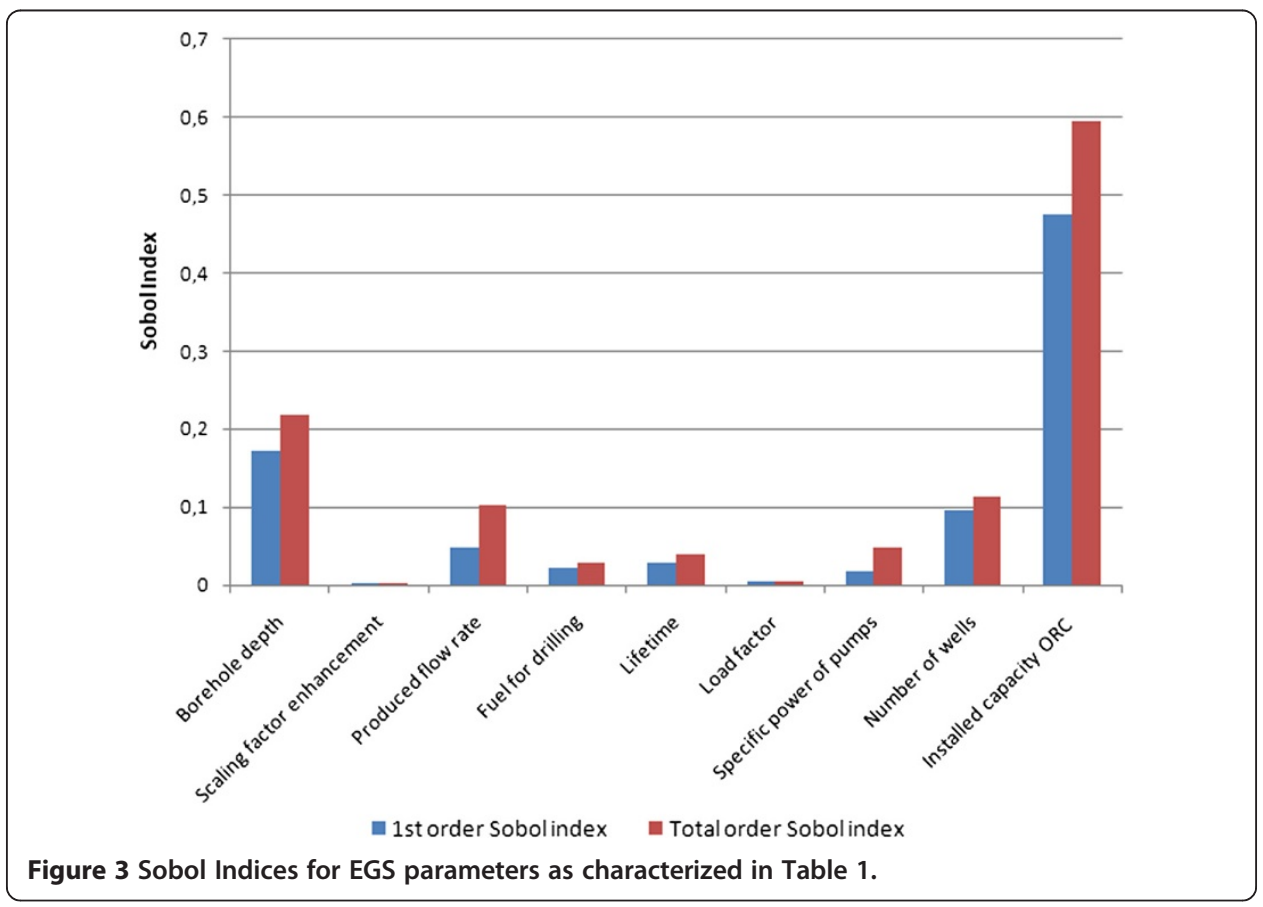


model still remains simple (see section 'Generation of the simplified model and results') and allows us to obtain more accurate environmental results. In any case, the choice of such parameters depends also on the possibility for the user of having easy access to the required data thus key parameter selection should be done in accordance between LCA expert and simplified model users.

\section{Generation of the simplified model and results}

The simplified model is designed to express the GHG performances as a function of the main key parameters (here set to three). Starting from the reference model (function of nine variables, Equation 3), we obtain our simplified model (Equation 4) by carrying out a regression analysis based on the three key variables and setting the other six at the value corresponding to the median of their variability interval. According to the description provided in Table 1, those median values are $f=62.5 \mathrm{~kg} / \mathrm{s}, d=5,000 \mathrm{MJ} / \mathrm{m}$, $\mathrm{LF}=0.9, \mathrm{LT}=30$ years, $\mathrm{SFe}=1.7, P_{\mathrm{p}}=6.1 \mathrm{~kW} /(\mathrm{kg} / \mathrm{s})$.

$$
\mathrm{GHG}_{\mathrm{EGS} \_ \text {simpl }}=f\left(P_{\mathrm{ORC}}, z, \mathrm{Nw}\right)=\frac{\mathrm{Nw} \times\left(\beta_{1} \times z+\beta_{2}\right)+\beta_{3} \times P_{\mathrm{ORC}}+\beta_{4}}{P_{\mathrm{ORC}}-\beta_{5}}
$$

with

$$
\begin{aligned}
& \beta_{1}=4.226\left[\mathrm{gCO}_{2} \mathrm{eq} /(\mathrm{m} \times \mathrm{h})\right] ; \beta_{2}=467.3\left[\mathrm{gCO}_{2} \mathrm{eq} / \mathrm{h}\right] ; \beta_{3}=5.472\left[\mathrm{gCO}_{2} \mathrm{eq} / \mathrm{kWh}\right] ; \\
& \beta_{4}=3,261.2\left[\mathrm{gCO}_{2} \mathrm{eq} / \mathrm{h}\right] ; \beta_{5}=381.2[\mathrm{~kW}]
\end{aligned}
$$

The $\beta_{i}$ constants are derived from the $\alpha_{i}$ of Equation 3 and correspond to the values of the GHG emissions of each part of the model.

The comparison between the results of the simplified model and those of the reference model can be observed in Figure 4. A Monte Carlo analysis has been performed over 50,000 simulations: each dot on the graph represents one simulation, namely one random set of the three key parameters representing a possible configuration for an EGS power plant. Higher concentrations of dots are highlighted by the red color. We observe that the points are aligned along the diagonal that indicates the equivalence between the results of the reference model and the simplified model, showing a coefficient of determination $\left(R^{2}\right)$ of $70 \%$ and a RMSE of $8.17 \mathrm{gCO}_{2} \mathrm{eq} / \mathrm{kWh}$. The results of the simplified model are very close to those of the reference model especially for lower GHG values.

The affinity between the simplified and the reference models increases with the number of key variables. For comparison, a two-parameter model based on $P_{\mathrm{ORC}}$ and $z$ (that together are responsible for about $65 \%$ of the variability of results, as discussed in section 'Key parameter identification') reach a $R^{2}$ of $52 \%$ and a RMSE of 12.10 $\mathrm{gCO}_{2} \mathrm{eq} / \mathrm{kWh}$. A four-parameter model based on $P_{\mathrm{ORC}}, z, \mathrm{Nw}$, and $f$ (together responsible for about $79 \%$ of the GHG variability) reach a $R^{2}$ of $81 \%$ and a RMSE of $6.14 \mathrm{gCO}_{2} \mathrm{eq} / \mathrm{kWh}$.

In order to assess the representativeness of the simplified model, a panel of eight EGS case studies from literature has been selected. Table 2 presents the values assumed by other authors for the key parameters.

Figure 5 shows a comparison between the results of our parameterized models and those from literature (red crosses). In this graph, for each case study, we set our three 


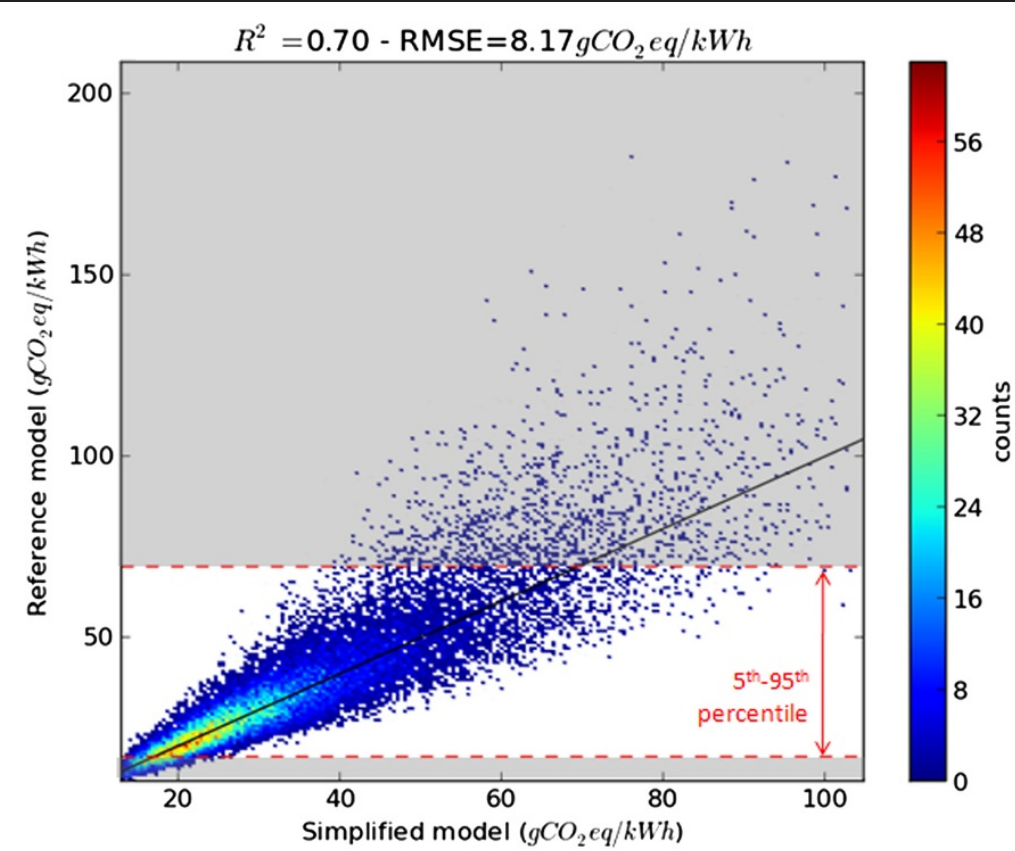

Figure 4 Comparison between the reference model and the simplified model. As presented in Figure 2, most of the results lie between 16 and $69 \mathrm{gCO}_{2} \mathrm{eq} / \mathrm{kWh}$ (5th and 95th percentile).

key variables (installed capacity, drilling depth, number of wells) at the values used by the author and we run our reference model (Equation 3) over 10,000 simulations. Hence, our result range (represented by the boxplot) depends on the variability of the other six non-key parameters. The middle line (the median) expresses the numerical result of the equation of the simplified model (Equation 4) where the six non-key

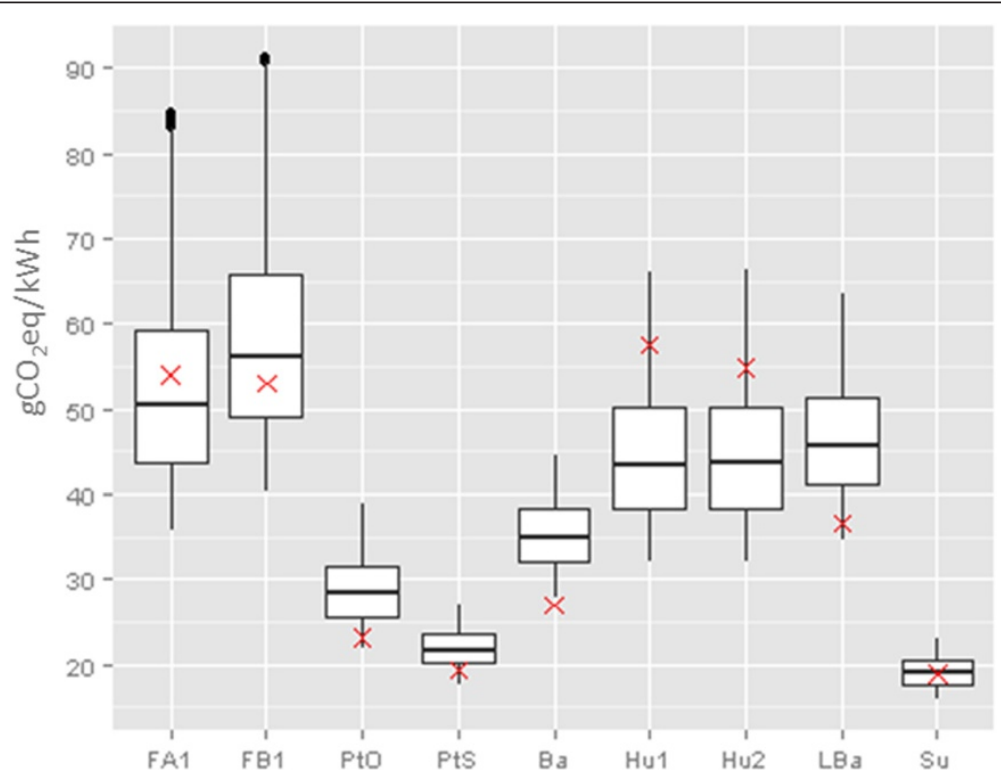

Figure 5 Comparison of the results of the parameterized models with literature. Red crosses indicate the estimates of the GHG performances proposed by other authors. The middle line of the boxplot (median of the distribution) indicates the result of the simplified model (Equation 4, three key parameters). The box and the whiskers indicate the result of the reference model (Equation 3) over 10,000 simulations with fixed values of the three key parameters. 
parameters have been set to their median values. The bottom and the top of the boxes shown in Figure 5 correspond respectively to the 25th and the 50th percentile, while the whiskers indicate the 5th and the 95th percentile.

\section{Discussion}

We now propose to discuss both the methodology to generate the parameterized models and the results.

- The characterization of the input parameters is an important step of the definition of the reference model (section 'Parameter description') and must be done with great care. Random sampling within these ranges may generate some unlikely scenarios, characterized by abnormally high (or low) GHG performances. For instance, an EGS power plant with the higher possible value for the flow rate $(f)$ but with the lower possible value for the installed power capacity $\left(P_{\text {ORC }}\right)$ (i.e., explicable only by an exceptionally low production temperature). In such a case, the GHG performances may have a fairly high value because of the limited quantity of electricity produced over the lifetime together with the high emissions related to the infrastructure. However, for our model, such cases belong to the tails of the statistical distribution, as $90 \%$ of the results are found on a limited range (16 to 69 $\mathrm{gCO}_{2} \mathrm{eq} / \mathrm{kWh}$ ), as shown in Figures 2 and 4.

- The comparison with nine case studies from literature is globally satisfactory. Discrepancies are principally due to the unavailability of the necessary data in literature (PtO, PtS cases) for our input parameters or to the characteristics of the EGS themselves, which may be at the edge (Hu1, Hu2 cases) or outside (Ba case) the scope of our reference model.

- The comparison (Figure 5) with the results of two of the case studies presented by Frick et al. (2010) is satisfactory. For example, when comparing with scenario A1 (FA1 in the figure), by setting $P_{\mathrm{ORC}}=1,240 \mathrm{~kW}, \mathrm{Nw}=2$, and $z=3,800 \mathrm{~m}$, the result of our simplified model (median of the boxplot) is $50 \mathrm{gCO}_{2} \mathrm{eq} / \mathrm{kWh}$. Given such values for the three key variables, when running our reference model 10,000 times we obtain results ranging mainly from 44 to $59 \mathrm{gCO}_{2} \mathrm{eq} / \mathrm{kWh}$ (25th and 75th percentile). These results are consistent with the value proposed by the author (54 $\mathrm{gCO}_{2} \mathrm{eq} / \mathrm{kWh}$ ).

- The GHG performances estimated by Platt et al. (2012) lie on the whiskers (slightly below the first quartile) of the statistical distribution of results of our model.

However, for these comparison (PtO and PtS in Figure 5), the $P_{\mathrm{ORC}}$ value to be used is established through a hypothesis regarding the ORC auxiliary power demand. This is assumed to amount to $20 \%$ of the generator's output. If the $P_{\text {ORC }}$ value was directly mentioned in Platt et al. publication, the results of the simplified model would have possibly been more accurate.

- The GHG performances proposed by Bauer et al. (2008) (Ba in Figure 5) are lower than those calculated by our reference model (value outside the whiskers). This can be explained by the fact that this author assumes a quite low power demand for the pumps of the geothermal loop (less than $4 \%$ of the installed capacity) while in our model, it amounts to about $12 \%$ of the installed capacity in this case (following the hypothesis reported in Table 1, consistent with the assumptions of the other 
authors). In our study, higher power consumption for the pumps implies less electricity delivered to the grid and higher GHG emissions per kWh. Our reference model is therefore quite conservative compared to Bauer et al.'s assumption when considering power consumption for the pumps.

- The simplified model slightly overestimates the GHG performances proposed by Lacirignola and Blanc (2013) (LBa in Figure 5). However, the result of this study lies within the lower whisker. Indeed, the median of the boxplot is calculated by setting the flow rate and the diesel consumption to their median value $(62.5 \mathrm{~kg} / \mathrm{s}$ and $5,000 \mathrm{MJ} / \mathrm{m}$, respectively). Those are higher compared to the author's assumptions (40 kg/s and $3500 \mathrm{MJ} / \mathrm{m}$, respectively). Hence, in our calculation, the drilling process generates higher emissions and the three wells are equipped with bigger pumps.

- The GHG performances proposed by the two case studies of Huenges (2010) (Hu1 and Hu2 in Figure 5) lie outside the 3rd quartile of the reference model's results. This can be explained by a low lifetime ( 20 years), while we assumed a statistical distribution centered on 30 years (Table 1). However, since few cases of our sample are to be characterized with a lifetime of 20 years (according to the variability range of 20 to 40 years presented in Table 1), Huenges' results lie within the whiskers.

- The case study presented by Sullivan et al. (2013) proposes a 20 MW EGS power plant equipped with 10 boreholes. Such characteristics are not considered in our variability ranges since the upper boundaries are set to $3.5 \mathrm{MW}$ and three wells. However, the GHG performances of our model (Su in Figure 5) are coherent with the estimation of the author. This can be explained by the fact that such parameters with 'unusual' values (power capacity and number of wells) are both key parameters of our model (by unusual, we mean a value far outside the boundaries we established). Indeed, for the calculations with the simplified model (Equation 4), $P_{\mathrm{ORC}}, \mathrm{Nw}$, and $z$ are input variables (to be set by the user). Hence, in this case, the model is able to take into account the high emissions related to the construction of ten boreholes as well as the high electricity production due to $20 \mathrm{MW}$ power output.

- Conversely, if the parameters with an unusual value are not key variables (e.g., an EGS with a load factor of 0.5), the simplified model provides a less accurate result (because LF is automatically assumed to be 0.9 with an uncertainty range between 0.85 and 0.95 ). This is also partially observed for the Hu1 and Hu2 cases: the lifetime assumed by Huenges (2010) is at the edge of our defined interval (20 years). Lifetime is not a key variable, namely it is not highly responsible for the variability of GHG performances. It is however influent on the GHG performance itself: therefore, the simplified model provides an underestimated result.

- As previously discussed, the simplified model invites the user to define only three parameters (installed capacity, drilling depth, and number of wells). However, using the formula of the reference model with nine parameters (Equation 3) might provide results closer to literature. For example, when comparing with Hul scenario, by setting the lifetime in addition to the three key parameters mentioned above, the error on Hu1 results decreases from 24\% (using the simplified model, Equation 4) to 4\% (setting four variables out of nine in the complete reference model, Equation 3).

Hence, by using the reference model (Equation 3), the user takes advantage of setting up to nine input variables, obtaining more accurate results. In case the data for the 
definition of many parameters are not easily accessible or available, the simplified formula provided by Equation 4 is a good alternative.

\section{Conclusions}

In this paper, we propose two parameterized models to assess the greenhouses gas emissions of EGS power plants. They constitute easy-to-use tools for estimating the GHG performances without undertaking a detailed LCA.

The reference parameterized model (Equation 3), based on nine parameters, encompasses a very large sample of possible technical setups and its results on GHG performances are consistent with the literature. Such a reference model is a major outcome of this research as it provides a generalized approach to estimate life cycle GHG emissions of EGS power plants.

The hierarchy among the variables and the form of the equations both depends on the architecture of the reference model and on the parameter description. Hence, our results may not be applicable to EGS power plants outside the scope of our analysis.

Very few LCI of EGS power plants are currently available in literature. Moreover, the values they propose are essentially based on the limited knowledge we have on EGS, given the few current industrial installations in Europe. The detailed LCIs used in this study, mainly obtained from Lacirignola and Blanc (2013), could be enriched with further data and therefore enlarge the scope of validity of the model proposed.

The simplified model (Equation 4), issued from a regression analysis carried out on a large sample of stochastic simulations of the reference model, is based on three key parameters which explain most of the variability on GHG results over the considered sample. This simplified model allows for a faster estimation of the GHG performances through a simple parameterized formula using easily accessible variables. Its robustness is assessed by satisfactory comparisons with the literature case studies proposed by several authors. It is worth to note that the validity range of the simplified model is identical to the reference one because of its construction mode based on a regression analysis.

The three-parameter model represents an example of application of the reference model and shows the possibility of further simplification. Indeed, the user can also perform a calculation by setting four to nine variables in Equation 3 (reference model): the reliability of the estimation increases with the number of customized parameters.

The choice of the number of key parameters for the simplified model results in a trade-off between accuracy and simplification. This choice depends also on the possibility for the user of having easy access to the required data thus key parameter selection should be done in accordance between LCA experts and simplified model users.

The application presented in this study confirms that the consistency and reliability of the simplified LCA methodology elaborated by Padey et al. (2013) so far applied only to the wind energy sector. Its utilization for the characterization of the environmental performances of other energy pathways is also to be considered.

The parameterized models presented in this study make it possible to estimate the environmental performances in terms of GHG emissions of EGS power plants without performing detailed and time-demanding LCAs. They represent a useful tool for environmental analysts and policy makers. This study aims at contributing to the discussions about EGS performances and the development of low-carbon solutions for electricity production. 


\section{Additional file}

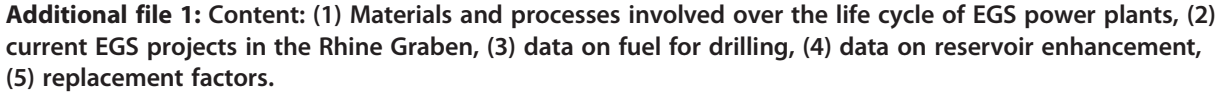

\section{Abbreviations}

$\mathrm{CO}_{2}$ : carbon dioxide; $d$ : fuel for drilling; EGS: enhanced geothermal system; f: produced flow rate; GHG: greenhouse gas; GSA: global sensitivity analysis; IPCC: Intergovernmental Panel on Climate Change; ISO: International Organization for Standardization; kWh el: kilowatt hour electrical; LCA: Life Cycle Assessment; LCl: Life Cycle Inventory; LF: Ioad factor;

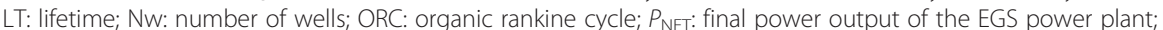
$P_{\text {ORC: }}$ installed capacity ORC; $P_{\mathrm{p}}$ : specific power of pumps; $R^{2}$ : coefficient of determination; RE: renewable energy; RMSE: root-mean-square error; SFe: scaling factor enhancement; SI: Sobol Index; $z$ : borehole depth.

\section{Competing interests}

The authors declare that they have no competing interests.

\section{Authors' contributions}

$M L$ defined the framework of the analysis and drafted the manuscript. BHM elaborated the computational code and performed the calculations. PP helped in the elaboration of the computational code and in reviewing the manuscript. IB conceived the study, coordinated it, and reviewed the manuscript. All authors read and approved the final manuscript.

\section{Acknowledgements}

The authors thank Dr. Camille Marini and Dr. Mathilde Marchand (MINES ParisTech) for their valuable comments and help as well as the two anonymous reviewers.

\section{Author details}

${ }^{1}$ Energy Networks and Renewable Energy Department, French Environment and Energy Management Agency (ADEME), 27 rue Louis Vicat, Paris 75737, France. ²Ecole Polytechnique, Route de Saclay, Palaiseau 91128, France. ${ }^{3}$ Energy Group, Institute for Environmental Sciences and Forel Institute, University of Geneva, 7 route de drize, Geneva 1227, Switzerland. ${ }^{4}$ O.I.E. - Centre Observation, Impacts, Energie, MINES ParisTech, PSL Research University, CS 10207 rue Claude Daunesse, 06904 Sophia Antipolis Cedex, France.

Received: 4 January 2014 Accepted: 20 May 2014

Published online: 10 October 2014

\section{References}

Ardente F, Beccali M, Cellura M, Lo Brano V (2008) Energy performances and life cycle assessment of an Italian wind farm. Renew Sustain Energ Rev 12:200-217

Bauer C, Dones R, Heck T, Hirschberg S (2008) Environmental assessment of current and future Swiss electricity supply options. Paper presented at the International Conference on the Physics of Reactors "Nuclear Power: A Sustainable Resource", Interlaken, 14-19 September 2008

Baumgärtner J (2011) Geothermie-ProjektInsheim. In: Abstracts of Soultz geothermal conference, Soultz-sous-Forets, 5-6 Oct 2011

Bayer P, Rybach L, Blum P, Brauchler R (2013) Review on life cycle environmental effects of geothermal power generation. Renew Sust Energ Rev 26:446-463

Bernstein L, Pachauri RK, Reisinger A, Intergovernmental Panel on Climate Change (2008) Climate change 2007 synthesis report. Intergovernmental Panel on Climate Change, Geneva

Bestec (2012) The Insheim Geothermal Project. http://www.bestec-for-nature.com/j2510m/index.php/en/projectsen/ insheim-en. Accessed Dec 2013

Blanc I, Padey P, Le Boulch D (2013) Meta-LCA models and simplified models for energy pathways: how different and for what use for decision makers? In: Abstracts of the SETAC Europe 19th LCA Case Study Symposium - LCA in market research and policy: harmonisation beyond standardisation, Rome, 11-13 Nov 2013

Ecoinvent Centre (2010) Ecoinvent data v2.2. In: Ecoinvent reports No.1-25. http://www.ecoinvent.org. Accessed Dec 2013

Frey M, Milles U (2007) Projektinfo 14/2007: Geothermal electricity generation in Landau. BINE Informationsdienst. http://www.bine.info/en/topics/publikation/geothermische-stromerzeugung-inlandau/. Accessed Oct 2014.

Frick S, Kaltschmitt M, Schröder G (2010) Life cycle assessment of geothermal binary power plants using enhanced low-temperature reservoirs. Energy 35:2281-2294

G.E.I.E. Exploitation Minière de la Chaleur (2002) GPK-3 daily drilling report. Soultz-sous-Forêts France

Gandy Inc (2004a) GPK-4 final drilling report. Soultz-sous-Forêts, France

Gandy Inc (2004b) GPK-4-rapports journaliers e Forage. Soultz-sous-Forêts, France

Genter A (2011) Overview of the scientific and technical research program done at Soultz during geothermal exploitation. In: Abstracts of Soultz geothermal conference, Soultz-sous-Forêts, 5-6 Oct 2011

Genter A, Baumgartner J, Cuenot N, Graff JJ, Kolbel T, Sanjuan B (2010) The EGS Soultz case study: lessons learnt after two decades of geothermal researches, Second European geothermal review, Mainz

Glassley WE (2010) Geothermal energy: renewable energy and the environment. CRC Press, Boca Raton

Gross J, Zeiß J, Grund M, Ritter J (2013) Microseismicity at two geothermal power plants at Landau and Insheim in the Upper Rhine Graben, Germany, Geophysical Research Abstracts 15:EGU2013-2742 
Heijungs R (1996) Identification of key issues for further investigation in improving the reliability of life-cycle assessments. J Clean Prod 4:159-166

Hettkamp D, Teza D, Michelet S, Baumgartner J, Baria R (2004) Technical report on the 2003 hydraulic testing and stimulation program. G.E.I.E. Exploration Minière de la Chaleur, Soultz-sous-Forêts

Hettkamp T, Baumgärtner J, Teza D, Gandy T, Frost J (2011) Production pump technology in the Landau and Insheim geothermal projects. In: Abstracts of Soultz geothermal conference, Soultz-sous-Forêts, 5-6 Oct 2011

Holm A, Blodgett L, Jennejohn D, Gawell K (2010) Geothermal energy: international market update. Geothermal Energy Association http://www.geoenergy.org/pdf/reports/gea_international_market_report_final_may_2010.pdf

Hondo H (2005) Life cycle GHG emission analysis of power generation systems: Japanese case. Energy 30:2042-2056

Huenges E (2010) Economic performance and environmental assessment. In: Geothermal energy systems: exploration, development and utilization. Wiley-VCH, Weinheim (Germany)

Hurtig E, Cermak V, Zui V (1992) Geothermal atlas of Europe. Hermann Haack, Gotha

looss B (2011) Revue sur l'analyse de sensibilité globale de modèles numériques. Journal de la Société Française de Statistique 152:3-25

ISO (2006a) ISO 14040:2006: Environmental management - life cycle assessment - principles and framework. International Organization for Standardization, Geneva

ISO (2006b) ISO 14044:2006: Environmental management - life cycle assessment - requirements and guidelines. International Standard Organization, Geneva

Jolliet O, Margni M, Charles R, Humbert S, Payet J, Rebitzer G, et al. (2003) IMPACT 2002+: a new life cycle impact assessment methodology. Int I Life Cycle Assess 8:324-330

LabEx G-EAU-THERMIE PROFONDE (2013) La géothermie profonde EGS - l'exemple de Soultz-sous-Forêts. http://labex-geothermie.unistra.fr/article200.html. Accessed Dec 2013

Lacirignola M, Blanc I (2013) Environmental analysis of practical design options for enhanced geothermal systems (EGS) through life-cycle assessment. Renew Energy 50:901-914

Lenzen M (2008) Life cycle energy and greenhouse gas emissions of nuclear energy: a review. Energy Convers Manag 49:2178-2199

Lund JW (2003) The USA geothermal country update. Geothermics 32:409-418

Moomaw W, Burgherr P, Heath G, Lenzen M, Nyboer J, Verbruggen A (2011) Annex II: Methodology. In IPCC Special Report on Renewable Energy Sources and Climate Change Mitigation. Cambridge University Press, Cambridge, United Kingdom and New York, NY, USA

Nami P, Schellschmidt R, Schindler M, Tischner T (2008) Chemical stimulation operations for reservoir development of the deep crystalline HDR/EGS system at Soultz-sous-Forêts (France). In: Paper presented at the Thirty-Second Workshop on Geothermal Reservoir Engineering, Stanford University, Stanford, 28-30 Jan 2008

Ness B, Urbel-Piirsalu E, Anderberg S, Olsson L (2007) Categorising tools for sustainability assessment. Ecol Econ 60:498-508

Pacca S, Sivaraman D, Keoleian GA (2007) Parameters affecting the life cycle performance of PV technologies and systems. Energ Pol 35:3316-3326

Padey P, Girard R, le Boulch D, Banc I (2013) From LCAs to simplified models: a generic methodology applied to wind power electricity. Environ Sci Technol 47:1231-1238

Pehnt M (2006) Dynamic life cycle assessment (LCA) of renewable energy technologies. Renew Energy 31:55-71

Perret E (2011) ECOGl, L'alliance de la géothermie et de l'industrie. In: Abstracts of Soultz geothermal conference, Soultz-sous-Forets, 5-6 Oct 2011

Platt M, Balon B, Appelhans K, Bracke R (2012) Ökobilanzdaten der geothermischen Strom- und Wärmeerzeugung in Deutschland imBereichTreibhausgase. In: Abstracts of the German Geothermal Congress, Karlsruhe, 13-16 November 2012

REN21 - Renewable Energy Policy Network for the 21st Century (2013) Renewables 2013 Global Status Report. REN21 Secretariat, Paris, France http://www.ren21.net/Portals/0/documents/Resources/GSR/2013/GSR2013_lowres.pdf

Schindler M, Baumgartner J, Gandy T, Hauffe P, Hettkamp T, Menzel H, Penzkofer P, Teza D, Tischner T, Wahl G (2010) Successful hydraulic stimulation techniques for electric power production in the Upper Rhine Graben, Central Europe. Paper presented at the World Geothermal Congress 2010, Bali, 25-29 April 2010

Schmidt B, Rogulic B, Ritter J (2010) Relationship between reduced injection rates and reduced induced seismicity - 3 years of field data from the commercial geothermal power plant of Landau (Germany). Proceedings of the workshop on induced seismicity, Luxembourg, 15-17 Nov 2010

Schmittbuhl J (2013) Géothermie, EOST Université de Strasbourg. http://labex-geothermie.unistra.fr/IMG/pdf/ presentation_geothermie_3a_2013.pdf. Accessed Dec 2013

Sobol IM (2001) Global sensitivity indices for nonlinear mathematical models and their Monte Carlo estimates. Math Comput Simul 55:271-280

Southern International Inc (2002) GPK-3 final report. Southern International Inc, Soultz-sous-Forêts, France

Sullivan JL, Clark C, Han J, Harto C, Wang MQ (2013) Cumulative energy, emissions and water consumption for geothermal power production. J Renew Sustain Energy 5:023127. http://dx.doi.org/10.1063/1.4798315

Varun, Bhat IK, Prakash R (2009) LCA of renewable energy for electricity generation systems - a review. Renew Sust Energ Rev 13(5):1067-1073

Warner E, O'Donoughue P, Heath G (2010) Harmonization of energy generation life cycle assessments (LCA). In: FY2010 LCA milestone report. National Renewable Energy Laboratory, Golden

doi:10.1186/s40517-014-0008-y

Cite this article as: Lacirignola et al: A simplified model for the estimation of life-cycle greenhouse gas emissions

of enhanced geothermal systems. Geothermal Energy 2014 2:8. 